\title{
Tek Serbestlik Dereceli Bir Teleoperasyon Sisteminde Kontrol Yöntemlerinin Performans Karşılaştırılması
}

\author{
Tayfun ABUT ${ }^{*}$, Servet SOYGÜDER ${ }^{2}$ \\ ${ }^{1}$ Makine Mühendisliği, Mühendislik-Mimarlık Fakültesi, Muş Alparslan Üniversite, Muş, Türkiye \\ ${ }^{2}$ Makine Mühendisliği, Mühendislik Fakültesi, Elazı̆̆, Türkiye \\ ${ }^{* 1}$ tayfunabut@gmail.com, ${ }^{2}$ ssoyguder@ firat.edu.tr
}

\begin{abstract}
Öz: Teleoperasyon sistemleri insan-robot etkileşimini(HRI) sağlayan sistemler olarak tanımlanmaktadır. Bu sistemlerin kontrolünün ilk olarak benzetim ortamında gerçekleştirilmesi, gerçek ortamda yapılacak deneyler öncesinde ve algoritma geliştirme aşamalarında tespit edilen hataların önlenmesi açısından önem taşımaktadır. $\mathrm{Bu}$ sistemlerin performans değerlendirilmelerinde konum ve kuvvet kontrolü önemli parametrelerdir. Bu çalışmada tek serbestlik dereceli ana (master) ve bağımlı(slave) robottan oluşan teleoperasyon sisteminin kontrolü hedeflenmiştir. Tek serbestlik dereceli robotların dinamik modelleri elde edilmiştir. Ayrıca bağımlı robotun hareketleri görselleştirmek için sanal ortamda görsel bir arayüz tasarlanmıştır. Bulanık mantık(Fuzzy Logic), PD tabanlı hesaplanmış tork kontrol(PD based-CTC) ve klasik PID kontrol yöntemleri kullanılarak sistemin iki yönlü gerçekleştirilmiștir. Bu yöntemler benzetim ortamında gerçekleştirilerek sonuçlar grafikler ve tablo şeklinde verilmiş ve irdelenmiştir.
\end{abstract}

Anahtar kelimeler: Teleoperasyon, Tek Serbestlik Dereceli Robot, Bulanık Mantık, PD-CTC, PID.

\section{Performance Comparison of Control Methods in a Single Degree of Freedom Teleoperation System}

\begin{abstract}
Teleoperation systems are defined as systems that provide human-robot interaction (HRI). The first control of these systems in the simulation environment is important in terms of preventing errors detected before the experiments in the real environment and in the algorithm development stages. Position and force control are important parameters in the performance evaluation of these systems. The aim of this study was to control the teleoperation system consisting of a single degree of freedom master and slave robot. Dynamic models of single degree of freedom robots were obtained. We also designed a visual interface in the virtual environment to visualize the movements of the slave robot. Bilateral control of the system was performed using Fuzzy Logic, PD-based calculated torque control(PD based-CTC) and classical PID control methods. These methods are carried out in the simulation environment and the results are given in the form of graphs and table.
\end{abstract}

Key words: Teleoperation, Single Degree of Freedom Robot, Fuzzy Logic, PD-CTC, PID.

\section{Giriş}

İnsan-robot etkileşimi (HRI) genel olarak, insan operatörlerinin amacını ileten ve görev tanımlarını robot yeteneklerine ve çalışma gereksinimlerine uygun bir dizi robot hareketi dizisine yorumlayan bir süreç olarak adlandırılmaktadır. HRI için uygun etkileşim yöntemlerinin ve arayüzlerin tanımlanması, robotların kilit faaliyet alanlarındaki insanları desteklemesi için gerekli olması nedeniyle zor bir çalışma alanıdır. Teleoperasyon sistemlerinde ve ameliyatlarda[1-4], dokunsal geribildirim arayüzleri[5-7] ve iki veya daha fazla etkileşimi birleştiren çoklu arayüzler modelleri[8-10], en sık kullanılan alanlardan bazılarıdır. Teleoperasyon insanları bilinmeyen ortamlardaki görevlere hazırlama ve geliştirme olanağı sağlayan bir robot teknolojisidir. Teleoperasyon sistemleri tehlikeli, düşük verimliliğe sahip veya insanların bulunamadığı ortamlarda çalışma potansiyellerine sahip oldukları için tasarlanmışlardır. Teleoperasyon sistemlerinin iki temel amacı vardır bunlar kararlılık ve şeffaflıktır. Aslında asıl amaç pozisyon, hız ve kuvvet sinyallerini ana robottan bağımlı robota aktarmak için kararlı bir kontrol şeması tasarlamaktır. Teleoperasyon sistemlerinin kararlılığı ve şeffaflığı, aktarılan bilginin miktarı ve türünden doğrudan etkilenir. Örneğin, konum ve hız sinyallerinin yanı sıra kuvvet sinyallerini iletmek mümkün olduğunda, daha verimli kararlılık ve şeffaflık mevcut olacaktır. Bunun nedeni, teleoperasyon sistemi kontrol yaklaşımlarında kuvvet sinyallerinin kullanılmasının bir avantajı olan sistem koşullarından daha doğru bilgi toplamaktır. Teleoperasyon çalışmalarının geniş bir çalışma yelpazesi olması dolayısıyla araştırmacılar tarafından

\footnotetext{
${ }^{*}$ Sorumlu yazar: tayfunabut@gmail.com. Yazarların ORCID Numaras1: ${ }^{1}$ 0000-0003-4646-3345, ${ }^{2}$ 0000-0002-8191-6891
} 
geçmişten günümüze kadar araştırılmakta ve çalışılmaktadır. Savunma sanayi, robotik cerrahi, medikal sanayi, nükleer çalışmalar ve simülatörler vb. [11-16] çalışma alanlarına sahiptir. Şekil 1'de iki yönlü teleoperasyon sisteminin blok diyagramı gösterilmiştir.

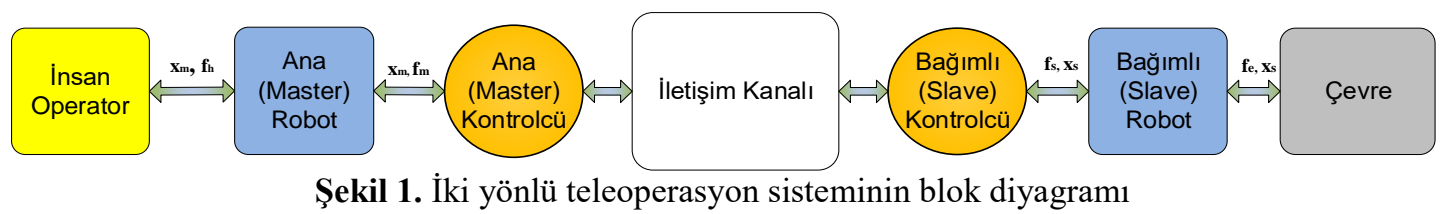

Bir teleoperasyon sistemi bir insan operatörü, bir ana(master) robot, bir iletișim kanalı, bir bağımlı(slave) robot ve bağımlı robotun etkileşim girdiği çevreden oluşur. Böyle sistemlerin temel amacı, kullanıcının manipülasyon yeteneklerini uzak bir ortama genişletmektir. Bu amaçla ana ve bağımlı robotlar, iletişim kanalı üzerinden kontrol sinyalleri alışverişinde bulunmakta ve kuvvet/güç etkileşimi, operatöre geri yansıtılmaktadır. Teleoperasyon sistemlerinde iki yönlü denetleyici tasarımları konusunda Yan ve Salcudean H-sonsuz'a dayalı genel bir tasarım teorisi sunmuşlardır[17]. Kikuchi ve arkadaşları zaman gecikmesini sabit tutmak için sanal zaman gecikmesi yöntemini kullandı. Buna ek olarak, ortam davranışını tahmin etmek ve öngörülen davranışı operatöre iletmek için ortam öngörücü görüntüleme sistemini kullanmıştır[18]. Park ve Cho bağımlı(slave) için bir kayan kipli denetleyicisi ve ana(master) robot için ise bir empedans denetleyicisi tasarlamıștır. Önerilen denetleyicinin geçerliliğini, 1-DOF ana(master) /bağımlı(slave) robottan oluşan iki yönlü teleoperasyon sistemini kullanarak simülasyon çalışmaları gerçekleştirmiştir[19]. Xiong ve diğ. bir telerobotu kontrol etmek için artırılmış gerçeklik temelli bir tahminsel görüntüleme metodu ve gerçek operatör-sanal robot etkileşimini kullanmıştır[20]. Itoh ve diğ. hareket ve kuvvet için sanal ortam modeli kullanılarak yeni bir öngörülü görüntüleme yöntemi geliştirmiştir. Önerilen yöntem temel olarak, öngörücü görüntünün üst üste getirilmiş görüntüsünü ve bağımlı robot bölgesinin gerçek görüntüsünü arttırmak için geliştirilmiştir[21]. Li ve diğ. çalışmalarında sanal bir ortam oluşturdular ve modelin parametrelerinin online olarak düzeltmesini sağlamaya çalışmıştır[22]. Lu ve diğ. çalışmalarında etkileşimler sırasında insan operatörü tarafından dokunsal görüntü oluşturma performansını artırmak için ayrıntılı bir enerji dengeleme metodu sunmuşlardır[23]. Shahdi ve Sirouspour, bilinen sabit veya zamanla değişen gecikme süresi altında iki yönlü teleoperasyonda stabiliteyi korurken yüksek düzeyde şeffaflık sağlayan adaptif kontrolörleri kullanmıştır. Bu kontrolörlerde sistemin modelini ve zaman gecikmesi bilgileri kullanılmıştır[24]. Abbink ve diğ. ileri-beslemeli kontrole dayanan bir teleoperasyon sistemini kontrol eden, hesaplamalı bir insan operatör modelinin geliştirmiştir[25]. Soyguder ve Abut endüstriyel robotların hareketini sanal ve gerçek zamanlı değişken zaman gecikmesi ile kontrol etmeye çalışmıştır. Konum izleme performansını ve sistemin kararlılığını analiz etmek için geliştirilmiş dalga değişkenleri yöntemi kullanmıştır[26]. Jafari ve diğ. iki yönlü kuvvet yansımalı teleoperasyon sisteminde meydana gelen zaman gecikmesi problemi dikkate alınmıştır. İletişim kanalını, zaman gecikmesinden bağımsız olarak pasif hale getiren bir anahtarlama kontrol yöntemi sunmuşlardır[27]. Teleoperasyon sistemlerinin birçok uygulama alanı olduğundan literatürde oldukça geniş bir yelpazeye sahiptir. Araştırmacılar çeşitli çalışmalar yapmaya devam etmektedirler[28-29]. Çoğu teleoperasyon sistemleri çok hassas görevlerde kullanıldığı için önemli bir yere sahiptir. Bu bağlamda robotik uygulamalarda tek yönlü veya iki yönlü kontrol ile kuvvet ve tork geri besleme son zamanlarda robotik alanında aktif şekilde araştırılmakta ve çalışılmaktadır. Bu çalışmada tek serbestlik dereceli ana (master) ve bağımlı(slave) robottan oluşan teleoperasyon sisteminin kontrolü hedeflenmiştir. Tek serbestlik dereceli robotların dinamik modelleri elde edilmiştir. Ayrıca bağımlı (slave) robotun hareketleri görselleştirmek için sanal ortamda görsel bir arayüz tasarlanmıştır. Bulanık mantık(Fuzzy Logic), PD tabanlı hesaplanmış tork kontrol (PD based-CTC) ve klasik PID kontrol yöntemleri kullanılarak sistemin iki kontrolü gerçekleştirilmiştir. Robotların tek ekseni kontrol edilmiştir. $\mathrm{Bu}$ yöntemler benzetim ortamında gerçekleştirilerek sonuçlar grafikler ve tablo şeklinde verilmiş ve irdelenmiştir. Simülasyon çalışmalarının sonuçları ile sistemin hareket kontrolü hakkında ileriye dönük faydalı bilgiler elde edilmiştir. Ayrıca bu çalışmada ana ve bağımlı robotların dinamik modelleri elde edilmiş, ayrıca kuvvet grafikleri de elde edilmiştir. Çalışmada kullanılan robot parametre değerleri Tablo 1'de gösterilmiştir.

\section{Sistemin Modellenmesi}

Teleoperasyon sisteminin dinamik denklemlerinin elde edilmesinde Lagrange-Euler yöntemi kullanılmıştır[30]. 
$\frac{d}{d t}\left(\frac{\partial L}{\partial \dot{q}_{i}}\right) \frac{\partial L}{\partial q_{i}}=\tau_{i}$

Robotlar tek serbestlik derecesine sahiptir. Sistemin hareket denklemleri kullanılarak robotun kontrolü gerçekleştirilmiştir. Tek serbestlik dereceli ana (master) ve bağımlı (slave) robotların hareket denklemleri aşağıda 2 ve 3 nolu denklemlerde verilmiştir.

$I_{m} \ddot{q}_{m}+b_{m} \dot{q}_{m}=f_{h}+\tau_{m}$

$I_{s} \ddot{q}_{s}+b_{s} \dot{q}_{s}=\tau_{s}-f_{e}$

$\ddot{q}_{i}, \dot{q}_{i}, q_{i}$ ve $\tau_{i}, f_{i}$ sirasiyla konum, hiz, ivme ve kontrol torkunu temsil etmektedir. $i \in\{m, s\}$ indisleri sırasıyla ana ve bağımlı robotları temsil etmektedir. $I_{m}$ ve $I_{s}$ atalet momentlerini $b_{m}$ ve $b_{s}$ ise robotların sönümleme katsayılarını göstermektedir. $\tau_{m}, \tau_{s}$ sırasıyla ana ve bağımlı robotlara etki eden tork ifadelerini temsil etmektedir. $f_{h}, f_{e}$ kullanıcı tarafından uygulanan ve çevreden sisteme etki eden bozucu kuvvetlere karşılık gelen kuvveti temsil etmektedir. Şekil 2'de tek serbestlik dereceli teleoperasyon sistemini oluşturan robotlardan bir tanesinin modeli gösterilmiştir.

Tablo 1. Tek serbestlik dereceli robotların fiziksel parametreleri

\begin{tabular}{|c|c|}
\hline Tanımlama \& Sembol & Değer \& Birim \\
\hline Kütle $\left(m_{m}\right)$ & $0.257 \mathrm{~kg}$ \\
\hline Kolun uzunluğu $\left(l_{m}\right)$ & $0.156 \mathrm{~m}$ \\
\hline Atalet $\left(I_{m}\right)$ & $0.012 \mathrm{kgm}^{2}$ \\
\hline Yay katsayısı $\left(k_{m}\right)$ & $0.01 \mathrm{~N} / \mathrm{m}$ \\
\hline Viskoz sönüm katsayısı $\left(b_{m}\right)$ & $0.0024 \mathrm{~N} \mathrm{~s} / \mathrm{m}$ \\
\hline Kütle $\left(m_{s}\right)$ & $0.257 \mathrm{~kg}$ \\
\hline Kolun uzunluğu $\left(l_{s}\right)$ & $0.156 \mathrm{~m}$ \\
\hline Atalet $\left(I_{s}\right)$ & $0.012 \mathrm{kgm}{ }^{2}$ \\
\hline Yay katsayısı $\left(k_{s}\right)$ & $0.01 \mathrm{~N} / \mathrm{m}$ \\
\hline
\end{tabular}

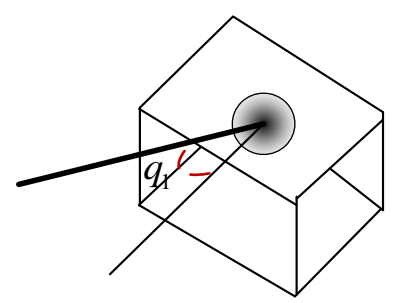

Şekil 2. Tek serbestlik dereceli robot modeli

İnsan operatör ile çevre arasında ilişki bir sanal duvar ile robotun uç kısmı arasındaki temas yay-damper sistemi şeklinde modellenmiştir. Şekil 3 'te kullanılan ana ve bağımlı robotun çevre ile etkileşim modeli gösterilmiştir. 


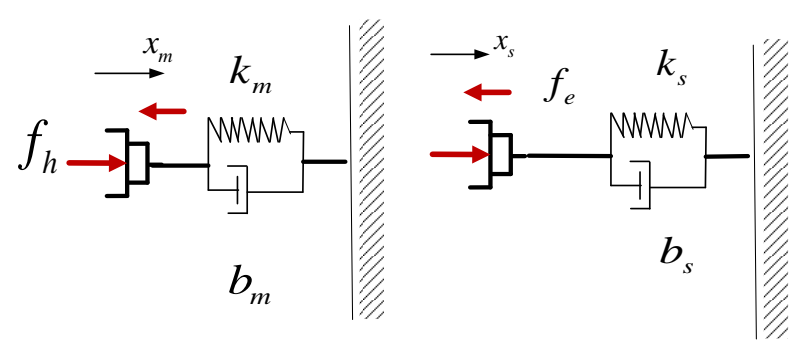

Şekil 3. Ana ve bağımlı robotların çevre ile etkileşim modeli

$f_{h}=k_{m}\left(x_{m}-x_{m d}\right)+b_{m}\left(\dot{x}_{m}-\dot{x}_{m d}\right)(a)$

$f_{e}=k_{s}\left(x_{s}-x_{m}\right)+b_{s}\left(\dot{x}_{s}-\dot{x}_{m}\right)(b)$

Burada a ve $b$ nolu denklemlerde $b_{m}, b_{s}, k_{m}, k_{s}$ sabitleri sırasıyla operatör ve çevre etkileşime girdiğinde sönüm ve yay sabiti katsayıların temsil etmektedir. $X_{\mathrm{m}}, \mathrm{X}_{\mathrm{md}}$ ve $\mathrm{x}_{\mathrm{s}}$ sirasiyla ana robotun konumunu, ana robotun istenen konumunu ve bağımlı robotun konumunu temsil etmektedir. $f_{e}$ ve $f_{h}$ ise ortaya çıkan kuvvetleri temsil etmektedir. $\mathrm{Bu}$ şekilde gösterilen model benzetim ortamında deneysel çalışmalar öncesinde kullanılmıştır.

\section{Arayüz Tasarımı}

Sanal bağımlı(virtual slave) robotun parametreleri Tablo 1'de verilmiştir. Bağımlı robotun arayüzü için Quarc yazılım kullanılmıştır. Bağımlı sanal robotun CAD modeli bir katı modelleme programında çizilmiş ve üç boyutlu (3D) model oluşturulmuştur. Öncelikle katı model programından Matlab/ Simulink ortamına aktarmak için, x3d formatına dönüştürüldü. Bir sonraki adımda ise bu parçaları ayrı ayrı veya vrlm biçiminde (sadece $3 \mathrm{dsmax}$ 'ta) bir araya getirildi. Matlab paket programına aktarılarak, Quarc Visulation blokları ile sistemin 3 boyutlu görseli oluşturuldu. Gerekli yön, konum, sahne ve ışık ayarları gerçekleştirilmiştir. Sanal robot için bu programda görsel arayüz tasarlandı. Şekil 4 'te tek serbestlik dereceli robotun oluşturulan görsel arayüzü gösterilmiştir.



Şekil 4. Tek serbestlik dereceli robot için oluşturulan görsel arayüz

\section{Kontrolör Tasarımı}

Kontrolör tasarlanırken, açısal hareket eden tek serbestlik dereceli robotun referans değeri takip etmesi hedeflenmiştir. Sistem klasik PID denetleyici, bulanık mantık (Fuzzy Logic) ve PD tabanlı hesaplanmış tork kontrol yöntemleri kullanılarak sistem denetlenmiştir.

\subsection{PID kontrol yöntemi}

Bu çalışmada kullanılan bir diğer yöntem klasik PID (oransal integral türevi) kontrol yöntemidir. PID (oransal integral türevi) kontrol yöntemi birçok uygulamada kullanılan eski bir yöntem olmasına rağmen iyi bir performans göstermektedir. Nispeten diğer kontrolcülere göre ayarlaması kolay olduğundan ve basit bir kontrol 
düzeneği olduğundan kullanımı yaygındır. Şekil 5'de PID geri beslemeli kontrol yönteminin blok diyagramı gösterilmiştir.



Şekil 5. PID geri beslemeli kontrol yönteminin blok diyagramı

$\mathrm{u}$ kontrolör çıkışı, $\mathrm{K}_{\mathrm{p}}$ oransal kazanç $\mathrm{K}_{\mathrm{i}}$ integral kazanç, $\mathrm{K}_{\mathrm{d}}$ türevsel kazanç ve e hata sinyali olarak adlandırılmaktadır. Bu çalışmada PID katsayılarının bulunmasında John G. Ziegler ve Nathaniel B. Nichols tarafından ileri sürülen Ziegler-Nichols yöntemi kullandı ve bu yöntem içerisinde de kapalı çevrim kontrol tipi kulland1[31-34]. Tablo 2'de Ziegler-Nichols yöntemi genel kontrol parametreleri gösterilmiştir.

Tablo 2. Ziegler-Nichols kapalı çevrim yöntemi ile elde edilen kontrol parametreleri

\begin{tabular}{|c|c|c|c|}
\hline Kontrol Türü & Kp & Ki & Kd \\
\hline $\mathrm{P}$ & $0.5 * \mathrm{~K}_{\mathrm{cr}}$ & $\infty$ & 0 \\
\hline PI & $0.4 * \mathrm{~K}_{\mathrm{cr}}$ & $0.8 * \mathrm{P}_{\mathrm{cr}}$ & 0 \\
\hline PID & $0.6 * \mathrm{~K}_{\mathrm{cr}}$ & $0.5 * \mathrm{P}_{\mathrm{cr}}$ & $0.125 * \mathrm{P}_{\mathrm{cr}}$ \\
\hline
\end{tabular}

\subsection{PD tabanlı hesaplanmış tork kontrol yöntemi(PD-CTC)}

Hesaplanmış tork kontrol yöntemi, robotların kontrolünde yaygın olarak kullanılan robust ve doğrusal olmayan bir denetleyicidir[35-36]. Bu kontrol sistemi geri beslemeli lineerleştirmeye dayanan doğrusal olamayan geri beslemeli kontrol yasasını kullanarak sistem için gerekli tork değerlerini hesaplamaktadır. Şekil 6'da PD tabanlı hesaplanmış tork kontrol(PD-Computed torque control (PD-CTC)) yöntemi blok diyagramı gösterilmiştir. $\mathrm{Bu}$ yöntemlerin kararlılık analizleri gerçekleştirilmiştir.

\subsection{Bulanık Mantık Kontrol Yöntemi}

Bulanık mantık(Fuzzy Logic) ve bulanık küme teorisi, 1960 yılında Azerbaycanlı Prof. Lotfi A. Zadeh (California University, Berkeley) tarafından ortaya atılmıştır. Bu çalışmasında, insanların bazı sistemleri makinelerden daha iyi denetleyebilmelerinin nedenini, insanların kesinlik ile ifade edilemeyen (belirsiz) bazı bilgileri kullanarak karar verebilme özelliğine sahip olmalarına bağlamıştır. Bulanık mantık işlemleri, bir problemin analizi ve tanımlanması, değişken kümelerin ve mantık ilişkilerinin geliştirilerek bulunan bilgilerin bulanık kümelere dönüştürülmesi ve modelin yorumlanması işlemlerinden oluşmaktadır[37-39]. Bulanık Mantık denetleyicisine ait blok diyagramı Şekil 7'de gösterilmiştir.

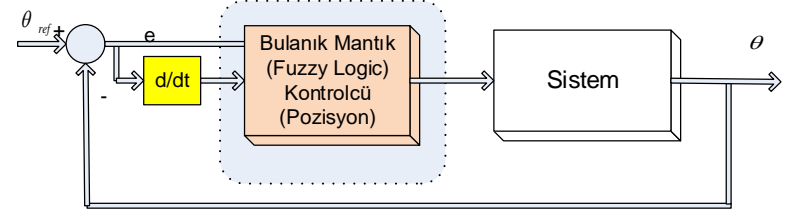

Şekil 7. Bulanık Mantık denetleyicisine ait blok diyagramı 
Kontrolör, hatayı ve hataların değişim oranını girdi olarak kullanır ve zamana göre değişen hata(e) ve hatanın türevine $(\dot{e})$ dayalı sistemin kontrolünü gerçekleştirmektedir. Önerilen bulanık mantık kontrolörü bir PID kontrolörü tarafından sağlanan kontrol performansını iyileştirmeyi amaçlamaktadır. Bir FLC' nin (Fuzzy lojik controller) kural tabanı, genellikle kontrol edilecek sistem hakkında bilgi sahibi uzman kişilerin sözel ifadelerinden elde edilen bir grup IF-THEN kuralından oluşmaktadır[40-43]. Kural tabanı, bir FLC' nin kalbi olarak nitelendirilmektedir. Çünkü diğer bütün birimler ve bileşenler bu kuralların makul ve verimli bir şekilde gerçekleştirilmesi için kullanılmaktadır. Bu sistem için oluşturulan kural tablosu ve üyelik fonksiyonları, ana ve bağımlı robotların minimum açı hata değerlerinin elde edilmesi amacıyla oluşturulmuştur. Bu sistemin denetimi için oluşturulan kural tabanı aşağıdaki Tablo 3' de görüldüğü gibi 9 kuraldan oluşmaktadır.

Tablo 3. FLC için Oluşturulan Kural Tabanı
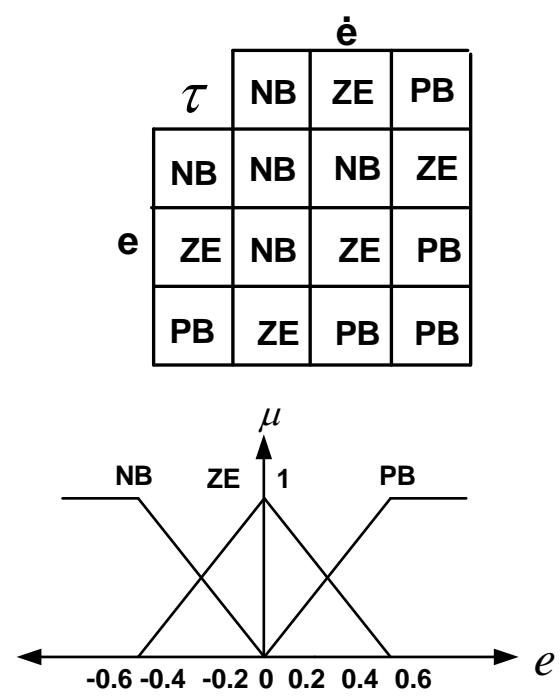

Şekil 8. Giriş değeri $e$ için tanımlanan üyelik fonksiyonları

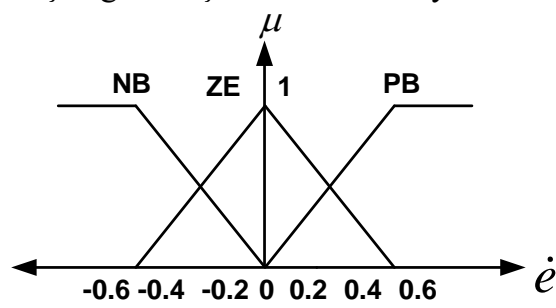

Şekil 9. Giriş değeri $\dot{e}$ için tanımlanan üyelik fonksiyonları

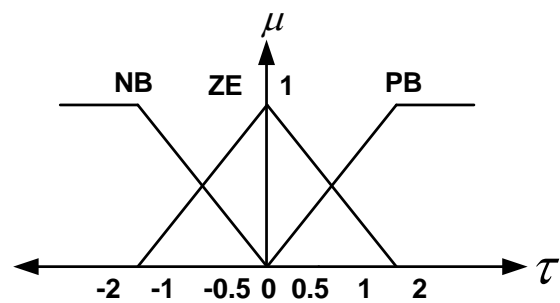

Şekil 10. Çıkış değeri $\tau$ için tanımlanan üyelik fonksiyonları

Şekil 8 ve 9'da sistemin giriş değerleri $e$ ve $\dot{e}$ için tanımlanan üyelik fonksiyonları gösterilmiştir. Şekil 10 'da çıkış değeri $\tau$ için tanımlanan üyelik fonksiyonları gösterilmiştir. Denetim algoritmalarında sistemin girişlerini $e$ (the error) hata ve $\dot{e}$ (the rate of change of error) hatanın değişim değerlerini oluşturmaktadır. Burada 
hata, sistemin çıkışları ile istenilen değerler arasındaki farklardır. Sistemin çıkışlarını ise hata ve hatanın zamana göre anlık değişim değerlerini minimize edecek şekilde sistemi tahrik eden motorlara uygulanan uygun tork değerleridir. Burada Bulanık mantık(Fuzzy Lojik) tipi denetiminde Mamdani metodu kullanılmıştır. Sistem denetim yapısı toplam tek giriş ve tek çıkıştan oluşmaktadır. Bu değer sistemin pozisyon bilgisidir. Burada denetimde hata $(e)$ ve hata değişimini $(\dot{e})$ minimize edecek şekilde gerekli kontrol sinyalleri $(\tau)$ üretmektedir. İlk olarak bulanık (fuzzy) kontrol için kullanılan üçgen (triangular) tipi üyelik fonksiyonuna ait grafikler Şekil 8, 9 ve 10 'da gösterilen giriş değerleri $e$ ve $\dot{e}$ için sirasıyla $\{-0.6,-0.4,-0.2,0,0.2,0.4,0.6\}$ ve $\{-0.6,-0.4,-0.2,0$, $0.2,0.4,0.6\}$ bu aralıktaki değerler kullanılmıştır. Aynı zamanda bulanık kontrole ait çıkış değeri $\tau$ için $\{-2,-1$, $-0.5,0,0.5,1,2\}$ bu aralıktaki değerler kullanılmıştır. Yukarıdaki tablolarda gösterilen kural tabanlarını oluşturan bulanık kontrol değişkenleri aşağıdaki gibi oluşturulmuştur. $e,(\dot{e}), \tau=\{$ hata, hata değişimi, denetim değişkeni tork \{NB (Negatif Büyük), ZE (Sıfır), PB (Pozitif Büyük)\}. FLC' ye ait giriş değerleri sırasıyla $\{-0.6,0.6\}$ ve $\{-$ $2,2\}$ aralığında belirtilmiştir. Giriş ve çıkış üyelik fonksiyonlarının tamamı üçgen tipi olarak alınmıştır.

\section{Benzetim (Simülasyon) çalışmaları}

Bu kısımda sistemin dinamik denklemleri kullanılarak benzetim çalışmaları yapılmıştır. Sistemin kontrol değişkenleri konum ve kuvvet parametreleridir. Bu çalışmada tek serbestlik dereceli haptik robotun benzetim çalışmaları gerçekleştirilmiştir. Tek serbestlik dereceli haptik-teleoperasyon çok serbestlik dereceli haptik robotlar ile gerçekleştirilen teleoperasyon çalışmalarının temelini oluşturmaktadır. Şekil 11' de ana ve bağımlı robotun çevre ile etkileşiminin benzetim modeli gösterilmiştir.

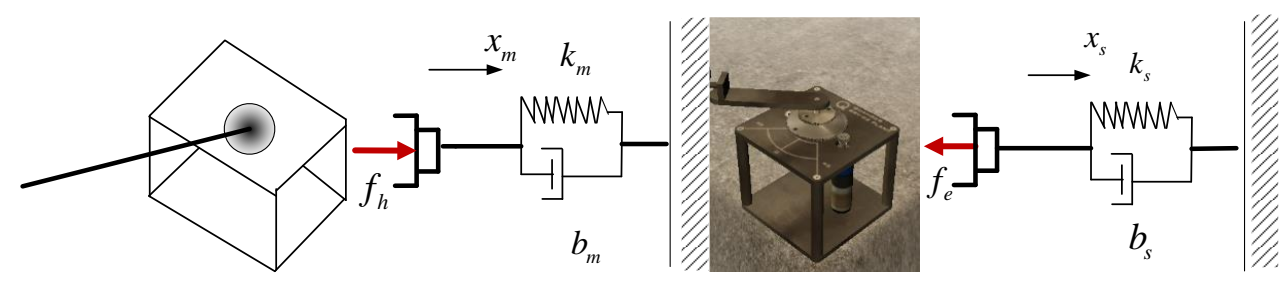

Şekil 11. Ana(master) ve bağımlı(slave) robotların çevre ile etkileşiminin benzetim modeli

Öncelikle robotların dinamik modelleri elde edilmiştir ve daha sonra bu modelleri çalışır hale getirilmiştir. Tek serbestlik dereceli ana ve bağımlı robotların hareket kontrollerinde Bulanık(Fuzzy) kontrol, PD tabanlı hesaplanmış tork kontrol metodu ve klasik PID kontrol yöntemleri kullanılmıştır. Bu kontroldeki amaç, ana robot tarafından üretilen referans yörüngeyi takip etmesidir. Ayrıca ana robot tarafindan üretilen konum ve hız değerlerinin, minimum konum ve hız hatası elde edilerek takip etmesidir. Bu bölümde kontrol yönteminin performans değerleri grafiksel olarak verilmiştir. Şekil 12,15 ve 18'de ana (master) ve bağımlı (slave) robotların sırasıyla bulanık mantık, PD tabanlı hesaplanmıs tork ve PID kontrol yöntemleriyle elde edilen pozisyon grafikleri verilmiştir. Şekil 13,16 ve 19'da ise ana (master) ve bağımlı (slave) robotların sırasıyla bulanık mantık, PD tabanlı hesaplanmış tork ve PID kontrol yöntemleriyle elde edilen hız grafikleri gösterilmiştir. Şekil 14,17 ve 20'de ise ana (master) ve bağımlı (slave) robotların sırasıyla bulanık mantık, PD tabanlı hesaplanmış tork ve PID kontrol yöntemleriyle elde edilen kuvvet grafikleri gösterilmiştir.

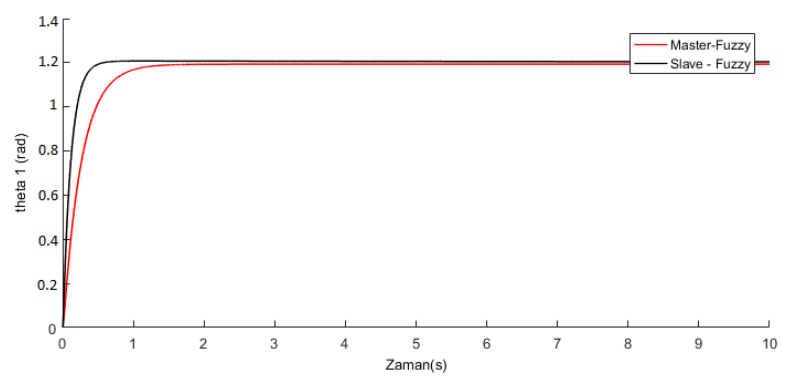

Şekil 12. Bulanık mantık(fuzzy logic) denetim yöntemi ile elde edilen robot eksen açısının cevabı 


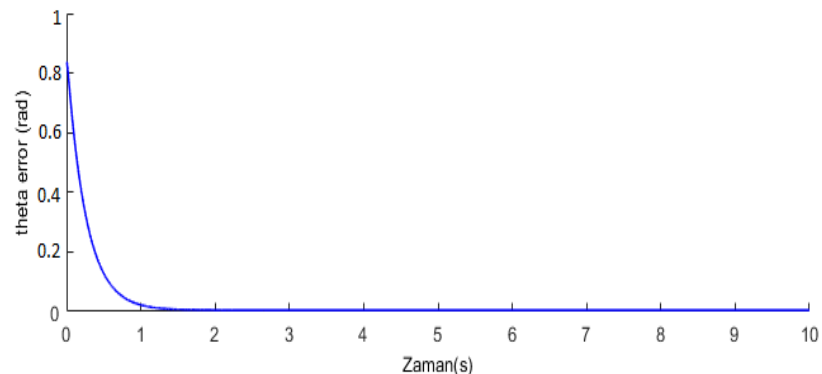

Şekil 13. Bulanık mantık(fuzzy logic) denetim yöntemi ile elde edilen hata cevabı

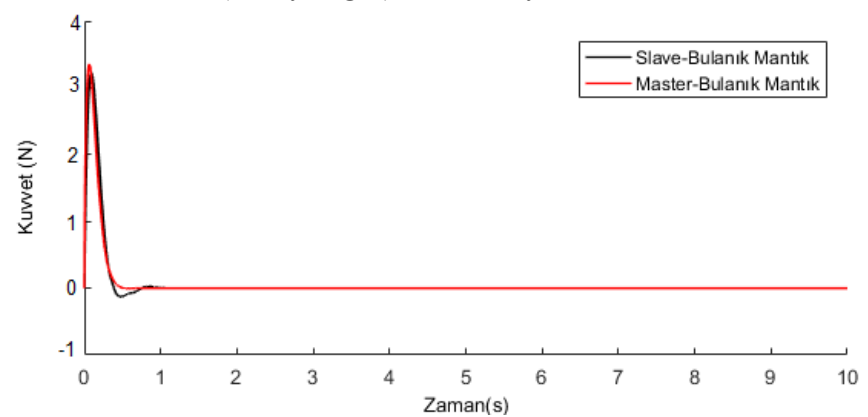

Şekil 14. Bulanık mantık(fuzzy logic) denetim yöntemi ile elde edilen kuvvet cevabı

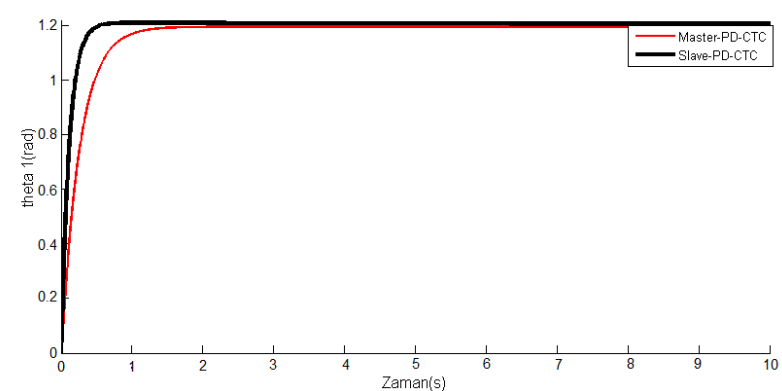

Şekil 15. PD tabanlı hesaplanmış tork kontrol yöntemi ile elde edilen robot eksen açısının cevabı

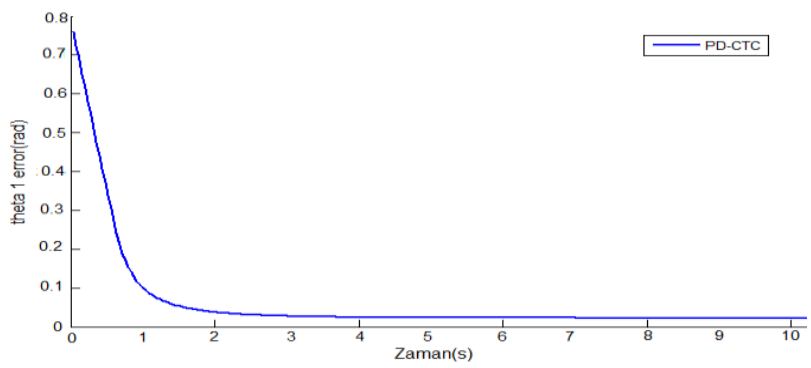

Şekil 16. PD tabanlı hesaplanmış tork kontrol yöntemi ile elde edilen hata cevabı 


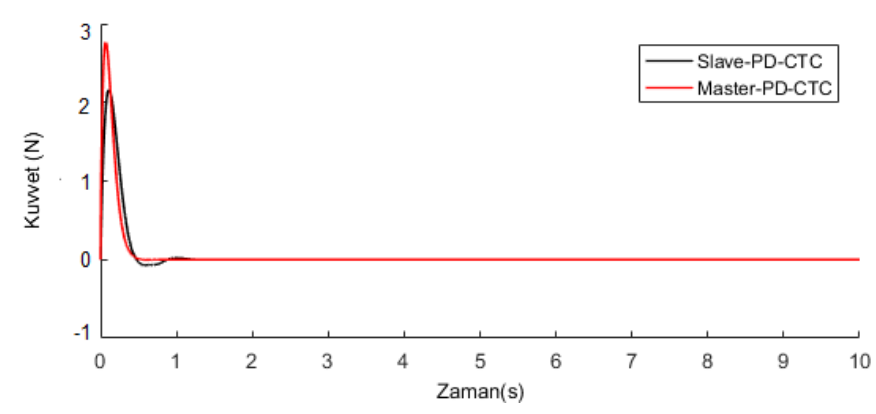

Şekil 17. PD tabanlı hesaplanmış tork kontrol yöntemi ile elde edilen kuvvet cevabı

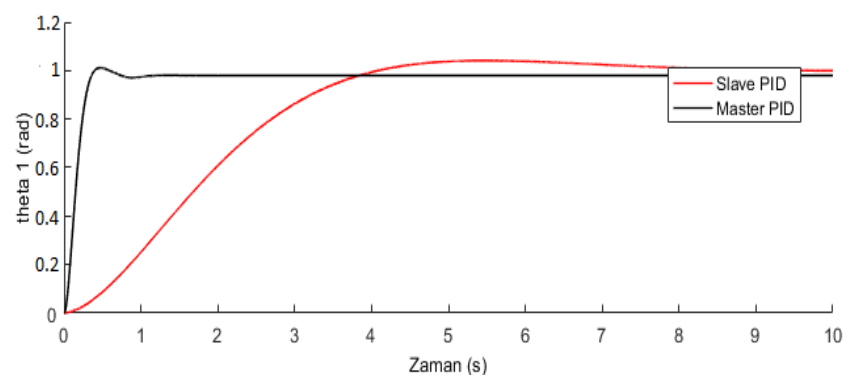

Şekil 18. PID denetim yöntemi ile elde edilen robot eksen açısının cevabı

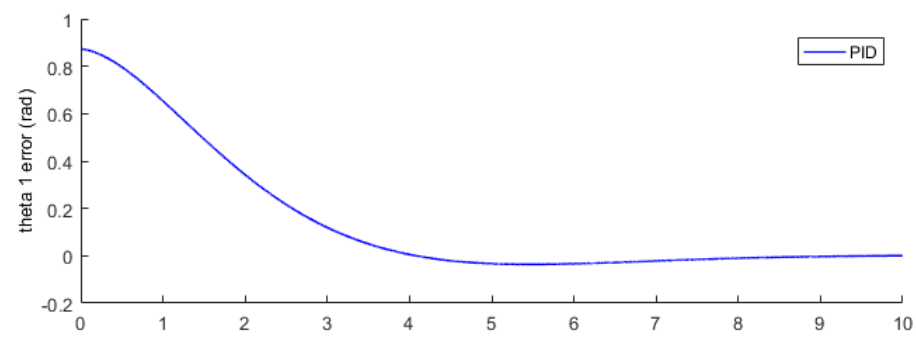

Şekil 19. PID kontrol yöntemi ile elde edilen hata cevabı

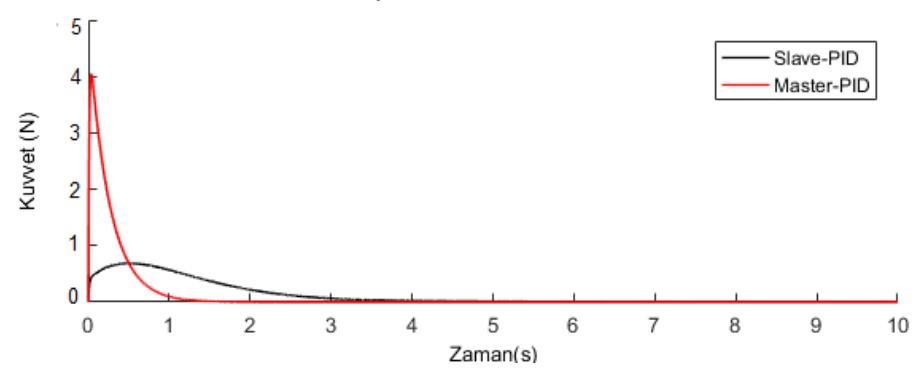

Şekil 20. PID kontrol yöntemi ile elde edilen kuvvet cevabı

Tek serbestlik dereceli teleoperasyon sisteminin kontrolünde kullanılan yöntemlerin performans karşılaştırması Tablo 4'te verilmiştir. Benzetim çalışmalarının süreleri 10 saniye alınmıştır. PD tabanlı hesaplanmış tork kontrol yöntemi klasik PID yöntemine göre daha düşük maksimum aşma, daha erken yerleşme süresi ve daha düşük sürekli rejim hatasına sahiptir. Karşılaştırılan açı cevaplarında PID kontrol yönteminin en büyük maksimum aşma genliğine, yerleşme süresine ve sürekli rejim hatasına sahip olduğu görülmüştür. Bulanık mantık kontrol yöntemindeki en düşük maksimum aşma genliğine, en düşük yerleşme süresine ve sürekli rejim hatasına performansı göstermiştir. Bulanık kontrol ana robot tarafindan üretilen referans değerini en iyi takip eden yöntem olduğu görülmüştür. En iyi kuvvet takibi ise yine bulanık mantık kontrol yöntemi ile elde edilmiştir. 
Tablo 4. Kontrol yöntemlerinin performans karşılaştırma tablosu

\begin{tabular}{|c|c|c|c|}
\hline $\begin{array}{c}\text { Kontrol } \\
\text { Yöntemi }\end{array}$ & $\begin{array}{c}\text { Yerleşme } \\
\text { Zamanı }\end{array}$ & $\begin{array}{c}\text { Maksimum } \\
\text { Aşma }\end{array}$ & $\begin{array}{c}\text { Sürekli } \\
\text { Rejim Hatası }\end{array}$ \\
\hline Bulanık(Fuzzy) Kontrol & 2 & 5.2 & 0.002 \\
\hline $\begin{array}{c}\text { PD tabanlı Hesaplanmış } \\
\text { Tork Kontrol Yöntemi }\end{array}$ & 4 & 8.24 & 0.008 \\
\hline PID & 9 & 15 & 0.4 \\
\hline
\end{tabular}

\section{Sonuçlar}

$\mathrm{Bu}$ çalışmada iki yönlü tek serbestlik dereceli teleoperasyon sistemin kontrolü gerçekleştirilmiştir. Sonuç olarak Bulanık mantık (Fuzzy Logic), PD tabanlı hesaplanmış tork kontrol yöntemi ve PID kontrol yöntemleriyle denetlenen tek serbestlik dereceli sistem için en kısa yerleşme süresine ve daha düşük genliğe sahip olması ayrıca sürekli rejim hatasının en düşük olduğu en iyi performansları göstermiştir. En iyi kuvvet takip performansı ise pozisyon cevaplarında olduğu gibi bulanık mantık kontrol yöntemi ile elde edilmiştir. Yöntemler arasında bu teleoperasyon sistemi için bulanık mantık kontrol yönteminin daha uygulanabilir olduğunu görülmüştür. Ayrıca PID kontrol yöntemi grafiklerde de görüldüğü gibi en kötü performansı göstermiştir. Elde edilen sonuçlar grafikler, tablo şeklinde verilmiş ve irdelenmiştir. Simülasyonlar sonucu sistemin hareketi hakkında ileriye dönük faydalı bilgiler elde edilmiştir. Gelecekte bu yöntem kullanılarak laboratuvar ortamında gerçek zamanlı çalışmalar yapilacaktır.

\section{Teșekkür}

Bu çalışma Fırat Üniversitesi Bilimsel Araştırma Projeleri (FÜBAP) 2015, MF.13.15 'nolu proje kapsamında desteklenmiştir.

\section{Kaynaklar}

[1] Ateş, G., Ronny M., Dede, M.İ.C., Design of a teleoperation scheme with a wearable master for minimally invasive surgery. New Trends in Medical and Service Robotics. Springer, Cham, 2019;45-53.

[2] Abut, T., Soyguder, S. Real-time control of bilateral teleoperation system with adaptive computed torque method., Industrial Robot: An International Journal, 2017; 44.3: 299-311.

[3] Abut, T., \& Soygüder, S., Haptic industrial robot control and bilateral teleoperation by using a virtual visual interface. In: 2018 26th Signal Processing and Communications Applications Conference (SIU). IEEE, 2018; p. 1-4.

[4] Kozıma, H., Yasuda, Y.; Nakagawa, C., Social interaction facilitated by a minimally-designed robot: Findings from longitudinal therapeutic practices for autistic children. In: RO-MAN 2007-The 16th IEEE International Symposium on Robot and Human Interactive Communication. IEEE, 2007. p. 599-604.

[5] Abut, T, Soygüder, S., Interface Design and Performance Analysis for a Haptic Robot, Mus Alparslan University Journal of Science, 2018; 6 (2), 553-560.

[6] Casper, J., Murphy, R.R., Human-robot interactions during the robot-assisted urban search and rescue response at the world trade center. IEEE Transactions on Systems, Man, and Cybernetics, Part B (Cybernetics), 2003, 33,3: 367-385.

[7] Wilcox, R., Nikola1dis, S.; Shah, J. Optimization of temporal dynamics for adaptive human-robot interaction in assembly manufacturing. Robotics, 2013, 441.

[8] Fong, T., Thorpe, C., Baur, C., Collaboration, dialogue, human-robot interaction. In: Robotics Research. Springer, Berlin, Heidelberg, 2003. p. 255-266.

[9] Holroyd, A. , Rich, C., Sidner, C.L, Ponsler, B., Generating connection events for human-robot collaboration, Proc. 20th IEEE Int. Symp. Robot Hum. Interact. Commun., Atlanta , 2011,pp. 241-246.

[10] Carıgnan, C., Tang, J., Roderıck, S., Development of an exoskeleton haptic interface for virtual task training. In: 2009 IEEE/RSJ International Conference on Intelligent Robots and Systems. IEEE, 2009. p. 3697-3702.

[11] Chen, J.YC, Haas, E.C., Barnes, M.J. Human performance issues and user interface design for teleoperated robots. IEEE Transactions on Systems, Man, and Cybernetics, Part C (Applications and Reviews), 2007, 37.6: 1231-1245.

[12] Strom, P., Hedman, L. , Sarna, L., Kjellin, A. , Wredmark, T., Fellander-Tsai, L., Early exposure to haptic feedback enhances performance in surgical simulator training: A prospective randomized crossover study in surgical residents, Surg. Endosc. 20(9), 2006, 1383-1388.

[13] Katsura S., Iida W., Ohnishi K. Medical mechatronics An application to haptic forceps, Annual Reviews in Control, 2005, 29.2: 237-245.

[14] Basdogan, C., De, S., Kim, J., Muniyandi, M., Srinivasan, M.A., Haptics in minimally invasive surgical simulation and training, IEEE Comput. Graph. Appl. 2004, 24.2: 56-64. 
[15] Wollacott, Andrew M., Merz JR, Kenneth M., Haptic applications for molecular structure manipulation. Journal of Molecular Graphics and Modelling, 2007, 25.6: 801-805.

[16] Zyda, M., Sheehan, J., Modeling and simulation: Linking entertainment and defense, National Research Council, Computer Science and Telecommunications Board Report., 1997.

[17] Yan, J., Salcudean, S. E. Teleoperation controller design using H/sub/spl infin//-optimization with application to motion scaling. IEEE Transactions on control systems technology, 1996, 4.3: 244-258.

[18] Kikuchi, J., Takeo, K., Kosuge, K., Teleoperation system via computer network for dynamic environment. In Proceedings. IEEE International Conference on Robotics and Automation,1998., Vol. 4, pp. 3534-3539.

[19] Park, J. H., Cho, H. C., Sliding-mode controller for bilateral teleoperation with varying time delay., IEEE/ASME International Conference on Advanced Intelligent Mechatronics, IEEE.,1999., pp. 311-316.

[20] Xiong,Y., Li, S., Xiet, M., Predictive display and interaction of telerobots based on augmented reality., Robotica, 2006, Vol.24, pp.447-453.

[21] Itoh, T., Yudate, K., Ito, S., Matsui, T., New predictive display method of motion and force information for network teleoperation without using virtual environment model. IEEE/RSJ International Conference on Intelligent Robots and Systems (IROS 2003) IEEE, 2003. p. 2815-2822.

[22] Li,H., Song, A., Virtual-environment modeling and correction for force-reflecting teleoperation with time delay.' IEEE Trans. On Industrial Electronics, 2007, 54.2: 1227-1233.

[23] Lu,X., Song, A., Stable haptic rendering with detailed energy-compensating control., Computers \& Graphics, 2008, 32.5: 561-567.

[24] Shahdi,A., Sirouspour, S., Adaptive control of bilateral teleoperation with time delay. Int. J. Intell. Mechatron. Robot. 2012, 2.1: 1-27.

[25] Wildenbeest, J. G. W., Abbink, D. A., Boessenkool, H., Heemskerk, C. J. M.,Koning, J. F., How operator admittance affects the response of a teleoperation system to assistive forces - a model analytic study and simulation. Fusion Eng. Des. 2013, 88.9-10: 2001-2005.

[26] Soyguder, S., Abut, T. , Haptic industrial robot control with variable time delayed bilateral teleoperation. Industrial Robot: An International Journal, 2016, 43.4: 390-402.

[27] Jafari, B. H., Spong, M. W., Passivity-based switching control in teleoperation systems with time-varying communication delay., American Control Conference (ACC). IEEE, 2017. p. 5469-5475.

[28] Abut, T, Soygüder, S ., Zaman Gecikmeli İnsan-Makine Etkileşimli Teleoperasyon Sisteminin Kontrolü. Frrat Üniversitesi Mühendislik Bilimleri Dergisi, 2018, 30.1: 193-202.

[29] Abut, T., Soyguder, S., Motion control in virtual reality based teleoperation system, Proceedings of the IEEE, Signal Processing and Communications Applications Conference SIU, 2015. p. 2682-2685.

[30] Hazewinkel, M., Lagrange equations (in mechanics), Encyclopedia of Mathematics, Springer, 2001.

[31] Ziegler, J.B., Nichols, N.B., The classic original paper: Optimum settings for automatic controllers, ASME Transactions, 1942, Vol. 64, pp. 759-768.

[32] Abut, T, Altı Serbestlik Dereceli Haptik Robot ile Teleoperasyon ve Sistem Dinamiği/Dynamic of System and Teleoperation with Six Degree of Freedom Haptic Robot, Firat Üniversitesi Yüksek Lisans Tezi, 2015.

[33] Hüseyınoğlu, M., Abut, T., Dynamic Model and Control of 2-Dof Robotic Arm, European Journal of Technique, 2017, 8.2: $141-150$.

[34] Abut, T., Control of a Dc Motor using Sensorless Observer Based Sliding Mode Control Method, International Journal of Engineering Trends and Technology, 2018, 66(2): 67-72.

[35] Middleton, R.H., Goodwin, G.C, Adaptive computed torque control for rigid link manipulators, 25th IEEE Conference on Decision and Control. IEEE, 1986. p. 68-73.

[36] Nguyen-Tuong, D., Seeger, M., Peters, J., Computed torque control with nonparametric regression models. In: 2008 American Control Conference. IEEE, 2008. p. 212-217.

[37] Zadeh, L. A. Fuzzy sets. Information and control, 1965, 8.3: 338-353.

[38] Zadeh, L.A., Fuzzy sets as a basis for a theory of possibility. Fuzzy sets and systems, 1978, 1.1: 3-28.

[39] Kilickap, E., Huseyinoglu, M., Yardimeden, A., Optimization of drilling parameters on surface roughness in drilling of AISI 1045 using response surface methodology and genetic algorithm, The International Journal of Advanced Manufacturing Technology, 2011, 52.1-4: 79-88.

[40] Abut, T, Soyguder, S, Real-time control and application with self-tuning PID-type fuzzy adaptive controller of an inverted pendulum, Industrial Robot: the international journal of robotics research and application, 2019, Vol. 46 Issue: 1, pp.159170. https://doi.org/10.1108/IR-10-2018-0206.

[41] Ozben, T., Huseyinoglu, M., Arslan, N., Fuzzy logic model for the prediction failure analysis of composite plates under various cure temperatures, Journal of the Brazilian Society of Mechanical Sciences and Engineering, 2014, 36.3: 443-448.

[42] Soyguder, S., Alli, H., An expert system for the humidity and temperature control in HVAC systems using ANFIS and optimization with fuzzy modeling approach, Energy and Buildings, 2009, Vol. 41No. 8, pp. 814-822.

[43] Soyguder, S., Karakose, M., Alli, H. "Design and simulation of self-tuning PID-type fuzzy adaptive control for an expert HVAC system", Expert Systems with Applications, 2009, Vol. 36No. 3, pp. 4566-4573. 